OPEN ACCESS

Edited by:

Anou M. Somboro,

University of KwaZulu-Natal, South

Africa

Reviewed by:

Linda Antionette Bester,

University of KwaZulu-Natal, South

Africa

Luther King Abia Akebe,

University of KwaZulu-Natal, South

Africa

*Correspondence:

Courage Kosi Setsoafia Saba csetsoafia@uds.edu.gh

Specialty section:

This article was submitted to Antimicrobial Resistance,

a section of the journal

Frontiers in Tropical Diseases

Received: 12 December 2021 Accepted: 31 January 2022

Published: 03 March 2022

Citation:

Karikari AB, Kpordze SW, Yamik DY and Saba CKS (2022) Ready-to-Eat

Food as Sources of Extended-

Spectrum $\beta$-Lactamase-

Producing Salmonella and

E. coli in Tamale, Ghana.

Front. Trop. Dis. 3:834048.

doi: 10.3389/fitd.2022.834048

\section{Ready-to-Eat Food as Sources of Extended-Spectrum $\beta$-Lactamase- Producing Salmonella and E. coli in Tamale, Ghana}

\author{
Akosua Bonsu Karikari ${ }^{1,2}$, Stephen Wilson Kpordze ${ }^{2,3}$, David Yembilla Yamik ${ }^{2,3}$ \\ and Courage Kosi Setsoafia Saba ${ }^{2,4 *}$
}

\begin{abstract}
1 Department of Clinical Microbiology, School of Medicine, University for Development Studies, Tamale, Ghana, 2 One Health Laboratory, Spanish Laboratory Complex, University for Development Studies, Tamale, Ghana, ${ }^{3}$ School of Food and Biological Engineering, Department of Food Science and Engineering, Jiangsu University, Zhenjiang, China, ${ }^{4}$ Department of
\end{abstract} Microbiology, Faculty of Biosciences, University for Development Studies, Tamale, Ghana

The existence of antimicrobial-resistant pathogens in ready-to-eat food is an emerging public health concern. We evaluated the presence of extended-spectrum $\beta$-lactamase (ESBL)-producing Escherichia coli and Salmonella species in street food in Tamale, as well as their antibiotic resistance profiles. Samples (42 salad samples and 71 fufu samples) purchased from 113 food vendors in the metropolis were analyzed by selective enrichment and plated onto chromogenic media. The Kirby-Bauer disk diffusion method was used to determine the susceptibility to antibiotics and phenotypic ESBL production. Positive phenotypic analysis for ESBL production was shown in 55.4\% (41/ $74)$ of E. coli and $44.6 \%$ (33/74) of Salmonella species. Antibiotic resistance characterization showed that ESBL strains from salad were completely sensitive to imipenem and chloramphenicol but mostly resistant to cefotaxime (70.0\%), ceftriaxone (85.0\%), and ceftazidime (70.0\%). Nonetheless, $24.1 \%$ of ESBL strains from fufu were resistant to imipenem and least resistant to gentamicin (3.7\%). In-vitro, E. coli were highly susceptible to ciprofloxacin, gentamicin, and erythromycin, as Salmonella species were more sensitive to imipenem and chloramphenicol; but in both species, resistance to $\beta$ lactam drugs was most prevalent. Multiple drug resistance was found in the entire ESBL strains of E. coli and Salmonella species (100\%) with respective multiple antibiotic resistance (MAR) indices of 0.56 and 0.48 presented by E. coli and Salmonella species. Our study demonstrated the occurrence of ESBL-producing pathogens in vegetable salads and fufu. The existence of pathogenic bacteria in food is a public health threat and becomes more alarming when the pathogens are endowed with resistant features; thus, policies to combat antimicrobial resistance should be implemented and food safety prioritized.

Keywords: ESBL, fufu, salad, antibiotic resistance, Tamale, Ghana 


\section{INTRODUCTION}

Universally, foodborne infections due to microbial pathogens are a significant cause of morbidity and mortality as food safety is progressively becoming a notable public health challenge. The global burden of foodborne infections is projected around 600 million, of which 420,000 individuals perish each year (1). Several reports on the prevalence of foodborne pathogens have been made, citing bacteria such as Staphylococcus, Bacillus, Salmonella, Shigella, Vibrio, Campylobacter, Escherichia coli, and Listeria sp. $(2,3)$. The contamination of food with microbial pathogens may occur in various ways including production, processing, distribution, retail marketing, and handling or preparation (4).

There is a growing apprehension on the emergence of foodborne pathogens that are resistant to antibiotics. Resistant pathogens present in the food chain, hospitals, and environment or water sources have been mentioned as main reservoirs of extended-spectrum beta-lactamase (ESBL) producers (5). ESBLs are enzymes capable of hydrolyzing various $\beta$-lactam antibiotics and thus facilitate resistance to penicillins, third- and fourth-generation cephalosporins, and monobactams. The genes encoding for the enzymes are generally found in the chromosomes and plasmids among the Enterobacteriaceae family, particularly E. coli and Klebsiella pneumoniae (6).

Dissemination of bacteria that produce ESBLs is no longer confined to human medicine but represents a budding problem in food safety (7). A WHO report and piloted investigations around the globe reveal the threat posed by ESBL-producing pathogens in both human medicine and the food chain (1). Lately, ESBL-producing pathogens not only are frustrating clinicians and clinical microbiologists but also are an enduring battle for food producers, veterinarians, and antimicrobial developers. Moreover, incessant use of antimicrobial drugs in agriculture and human medicine that is particularly critical in developing countries is considered the prime mover in the emergence and persistence of antibiotic-resistant bacteria $(8,9)$.

In Ghana, ESBL detection in pathogens mainly features clinical strains. Thus, a record of their incidence in food is next to nothing, which could be a public health risk. The existence of ESBL-producing strains in food is an important risk factor for human health; hence, it is appropriate to analyze food due to its epidemiological significance. Collectively, antimicrobial resistance studies in the northern sector of Ghana are noticeably below average and the few point up resistance in human and veterinary medicine. Our aim therefore was to evaluate the existence of multiple drugresistant ESBL-producing Salmonella and E. coli strains from ready-to-eat food (salad and fufu) in the Tamale metropolis of the Northern Region of Ghana. Fufu is a local delicacy patronized by the young and old that is made from either pounded yam or pounded cassava with plantain or cocoyam. Salad is any food preparation comprising a blend of chopped or sliced vegetables that provides a good source of minerals. Salad is a major constituent of most street food in Ghana.

\section{MATERIALS AND METHODS}

\section{Study Area}

The study was conducted in the Tamale metropolis, which is the capital town of the Northern Region of Ghana and located north of Accra, the national capital, by a distance of $600 \mathrm{~km}$. It is the most populous metropolis in northern Ghana with an estimated population of 950,124. One hundred thirteen (113) major and minor food vendors from the Tamale metropolis were the sampling sites considered in the study.

\section{Study Design}

We conducted a cross-sectional study using random sampling approach where each food vendor had an equal chance of being selected within the sampling frame. The study expanded its design to cover most (80\%) food joints in the metropolis. The research was conducted from July 10, 2015, to January 30, 2016. Permission was sought from the owners or management of fast food joints before sampling.

\section{Sample Collection Technique}

Fufu and salad samples were purchased from 113 street food vendors in the Tamale metropolis and aseptically collected in sterile zip-lock bags, labeled, kept on ice in an ice chest, and transported to the laboratory for analysis within $2 \mathrm{~h}$.

\section{Isolation and Identification of $E$. coli and Salmonella Species}

The detection of Salmonella and E. coli was done following the conventional culture-based methods according to the International Organization for Standardization-ISO (10) protocol (ISO 6579:2002) with slight modification.

\section{Pre-Enrichment for Salmonella Identification}

Here, $25 \mathrm{~g}$ of each sample was homogenized with $225 \mathrm{ml}$ of Peptone Water (Oxoid, Basingstoke, UK) in a sterile zip-lock bag for $45 \mathrm{~s}$. The homogenates were incubated for $16-20 \mathrm{~h}$ at $35^{\circ} \mathrm{C}-37^{\circ} \mathrm{C}$.

\section{Selective Enrichment for Salmonella Identification}

Here, $100 \mu \mathrm{l}$ of the incubated homogenate was transferred in a form of three drops onto prepared Modified Semi-Solid Rappaport Vassiliadis (Oxoid, CM1112, Basingstoke, UK) in plates and followed incubation at $42^{\circ} \mathrm{C}$ for $18-24 \mathrm{~h}$. Plates showing a gray halo with motile growth were selected and streaked onto Xylose Lysine Deoxycholate agar-XLD (Oxoid, Basingstoke, UK) and incubated at $37^{\circ} \mathrm{C}$ for $24 \mathrm{~h}$.

\section{Isolation of E. coli on Selective Media}

Here, $25 \mathrm{~g}$ of every sample was homogenized with $225 \mathrm{ml}$ of Peptone Water in a sterile zip-lock bag for $45 \mathrm{~s} ; 1 \mathrm{ml}$ of each homogenate was inoculated on a plate of CHROM agar ${ }^{\mathrm{TM}} \mathrm{E}$. coli (CHROMagar, Paris, France) at $37^{\circ} \mathrm{C}$ for $24-48 \mathrm{~h}$.

\section{Preliminary Identification of Salmonella and E. coli}

One characteristic colony appearing pink with black center on XLD was selected as presumptive Salmonella isolate. Colonies 
appearing blue on CHROM agar were also chosen for E. coli per the manufacturer's guideline. All selected colonies for both Salmonella and E. coli were streaked on Nutrient agar (Oxoid, Basingstoke, UK) and incubated for $24 \mathrm{~h}$ at $37^{\circ} \mathrm{C}$ for further biochemical confirmation.

\section{Biochemical Confirmation}

Confirmation of isolated Salmonella and E. coli was done based on three biochemical tests. Prepared slants of Simmons Citrate agar and Triple Sugar Iron agar (Oxoid, Basingstoke, UK) were inoculated by using the butt stubbing and slant streaking approach, and tubes were incubated with loose caps at $37^{\circ} \mathrm{C}$ for $18-24 \mathrm{~h}$, for both citrate utilization and hydrogen sulfide tests, respectively. Indole test was used to further confirm the pathogens.

\section{Phenotypic Screening of Isolates for ESBL Production}

Production of ESBL was tested by adopting Clinical and Laboratory Standards Institute's (CLSI) recommendation of measuring the inhibitory zone diameter of a cefotaxime disk and a cefotaxime/clavulanic acid disk or a ceftazidime and a ceftazidime/clavulanic acid disk (Oxoid, Basingstoke, UK). Confirmation of ESBL was performed using both cefotaxime $(30 \mu \mathrm{g})$ and ceftazidime $(30 \mu \mathrm{g})$ alone and in merger with clavulanic acid, ceftazidime plus clavulanic acid $(30 / 10 \mu \mathrm{g})$, and cefotaxime plus clavulanic acid $(30 / 10 \mu \mathrm{g})$. A $\geq 5-\mathrm{mm}$ difference in the zone diameter for any of the tested antibiotics was considered a positive result (11). E. coli ATCC 25922 was used as the control strain.

\section{Antibiotic Susceptibility Test}

Susceptibility of E. coli and Salmonella sp. to 11 antimicrobial agents was performed using the disk diffusion method on Mueller-Hinton agar plates according to the European Committee on Antimicrobial Susceptibility Testing guidelines and breakpoints (EUCAST, 2015). Antibiotics (Oxoid, Basingstoke, UK) used in this study include ampicillin $(10 \mu \mathrm{g})$, ciprofloxacin $(5 \mu \mathrm{g})$, cefotaxime $(30 \mu \mathrm{g})$, tetracycline $(30 \mu \mathrm{g})$, gentamicin $(10 \mu \mathrm{g})$, amoxicillin/clavulanic acid $(30 \mu \mathrm{g})$, sulfamethoxazole/trimethoprim (SXT; $25 \mu \mathrm{g}$ ), erythromycin $(15 \mu \mathrm{g})$, ceftriaxone $(30 \mu \mathrm{g})$, nitrofurantoin (100 $\mu \mathrm{g})$, and ceftazidime $(10 \mu \mathrm{g})$. Multiple drug resistance was defined as resistance to three or more classes of antibiotics. Multiple antibiotic resistance (MAR) index was calculated as the ratio between the number of antibiotics that an isolate is resistant to and the total number of antibiotics the organism is exposed to (12). It was computed using the formula $\mathrm{a} /\left(\mathrm{b}^{*} \mathrm{c}\right)$, where $a$ is the aggregate antibiotic resistance score of all isolates from the sample, $b$ is the number of antibiotics, and $c$ is the number of isolates from the sample.

\section{Data Analysis}

Data were entered into IBM Statistical Package for the Social Sciences version 20. Descriptive statistics including frequencies and percentages were used and presented in tables and graph. Associations between categorical outcome variables were conducted using the Pearson chi-square test at the $95 \%$ significance level. A two-tailed p-value $\leq 0.05$ was considered statistically significant.

\section{RESULTS}

\section{Prevalence of ESBL-Producing E. coli and Salmonella in Food}

One hundred thirteen (113) samples comprising 71 fufu and 42 vegetable salads were screened, of which $48 \mathrm{E}$. coli and 23 Salmonella sp. were recovered from fufu and 10 E. coli and 32 Salmonella sp. from salads. Phenotypically, ESBLs were detected in approximately $55.0 \%$ (41) of the E. coli strains and close to $45.0 \%$ (33) in Salmonella species (Table 1).

\section{Antibiotic Susceptibility Pattern of ESBL and Non-ESBL Pathogens}

ESBL strains from salad showed high resistance to the thirdgeneration cephalosporins, ceftriaxone (85.0\%), ceftazidime (70.0\%), and cefotaxime $(70.0 \%)$ but $20.0 \%$ to cefoxitin and $70.0 \%$ to cefepime. Resistance to erythromycin and SXT was $65.0 \%$ each and to ampicillin, Augmentin, and tetracycline, less than $50.0 \%$ was recorded. No resistance $(0.0 \%)$ was observed among the ESBLs against chloramphenicol and imipenem. Although the difference in resistance of ESBL and non-ESBL strains was statistically insignificant $(p=0.975)$, the non-ESBL strains showed greater resistance to ampicillin, Augmentin, tetracycline, cefotaxime, cefoxitin, and chloramphenicol. Largely, resistance was common in the ESBL strains (Table 2).

\section{Susceptibility Profile of ESBL and Non- ESBL Pathogens Obtained From Fufu}

The ESBL strains isolated from fufu exhibited high resistance to ceftriaxone (92.6\%), ceftazidime (96.3\%), cefotaxime $(100 \%)$, cefepime (100\%), ampicillin (90.7\%), Augmentin (74.1\%), and tetracycline $(72.2 \%)$. Resistance was $24.1 \%$ to imipenem and below $5 \%$ to gentamicin. The non-ESBL species were commonly resistant to ampicillin, ceftazidime, ceftriaxone (82.4\% each), and tetracycline $(70.6 \%)$ and less common to gentamicin $(0 \%)$ and

TABLE 1 | Prevalence of ESBL- and non-ESBL-producing E. coli and Salmonella sp. from food.

\begin{tabular}{lcc}
\hline Type of strain & E. coli (\%) & Salmonella (\%) \\
\hline ESBL $(n=74)$ & $41(55.4)$ & $33(44.6)$ \\
Non-ESBL $(n=39)$ & $17(43.6)$ & $22(56.4)$ \\
Total $(113)$ & $58(51.3)$ & $55(48.7)$
\end{tabular}


TABLE 2 | Resistance pattern of salad isolates.

\begin{tabular}{|c|c|c|c|c|c|c|c|c|c|c|c|c|c|c|c|}
\hline \multirow[t]{2}{*}{ Type of strain } & \multicolumn{14}{|c|}{ Antibiotic \% Resistance } & \multirow[t]{2}{*}{$P$ value } \\
\hline & GN & SXT & AMP & AMC & CIP & TET & CRO & CAZ & ERY & CTX & FOX & FEP & $\mathrm{C}$ & IPM & \\
\hline ESBL $(n=20)$ & 15.0 & 65.0 & 45.0 & 40.0 & 30.0 & 40.0 & 85.0 & 70.0 & 65.0 & 70.0 & 20.0 & 70.0 & 0.0 & 0.0 & 0.975 \\
\hline $\begin{array}{l}\text { Non- } \\
\text { ESBL }(n=22)\end{array}$ & 9.1 & 59.1 & 59.1 & 63.6 & 9.1 & 54.6 & 63.6 & 68.2 & 40.9 & 77.3 & 36.4 & 54.6 & 4.6 & 0.0 & \\
\hline
\end{tabular}

GN, gentamicin; SXT, trimethoprim/sulfamethoxazole; AMP, ampicillin; AMC, Augmentin; CIP, ciprofloxacillin; TET, tetracycline; CRO, ceftriaxone; CAZ, ceftazidime; ERY, erythromycin; CTX, cefotaxime; FOX, cefoxitin; FEP, cefepime; C, chloramphenicol; IPM, imipenem.

imipenem (17.7\%). Statistically, resistance difference in the ESBL strains and non-ESBLs was not significant; however, ESBL strains generally showed more resistance (Table $\mathbf{3}$ ).

\section{Susceptibility Profile of ESBL-Producing E. coli and Salmonella Species From Salads and Fufu}

Gentamicin, chloramphenicol, and imipenem appeared effective against the Salmonella ESBL strains with a recorded resistance range of $3.0 \%-15.2 \%$. The E. coli isolates on the other hand showed least resistance to gentamicin (0\%) and below $10.0 \%$ to erythromycin and ciprofloxacin. Salmonella and E. coli ESBL strains were more sensitive to imipenem, ciprofloxacin, and gentamicin. Resistance among the E. coli strains were significantly higher, $\mathrm{p}=0.002$ (Table 4). Multiple drug resistance was found in all (100\%) ESBL and non-ESBLproducing E. coli and Salmonella species with respective MAR indices of 0.56 and 0.48 presented by E. coli and Salmonella species (Table 5).

\section{DISCUSSION}

Street food vending is a thriving industry in Ghana particularly in urban and peri-urban areas of the country. The trade is however perceived to be a repertoire for disseminating foodborne pathogens. We examined E. coli and Salmonella spp. recovered from popular street food (fufu and vegetable salads) in Tamale metropolis to determine the extent of contamination with ESBLproducing strains. More than half of the E. coli isolates and almost $45 \%$ of Salmonella species were ESBL producers. This occurrence is not a deviation from literature reports establishing vegetables as sources of ESBL pathogens (13-15). The presence of ESBL strains in vegetables represents a viable course for passing on resistance genes in the community through the consumer $(16,17)$. Our contamination rate in salad vegetables sharply contrasts a Nepal study where $7.6 \%$ and $13.8 \%$ were detected respectively in E. coli and Salmonella strains (18). The disparity may be pointed to the distinct sample sources, i.e., hotels and restaurants in Nepal vs. street food in Tamale. Furthermore, food in hotels and restaurants may be hygienically handled than street food, thus reducing the risk of exposure to pathogens. Our results once more are inconsistent with prevalence rates reported by Mesa et al. (19), Raphael et al. (16), and Reuland et al. (17), who documented between $6 \%$ and $12 \%$ and Zurfluh et al. (7) who reported an average of $25.4 \%$ in vegetables sourced from Dominican Republic, India, Thailand, and Vietnam. In Modena, Italy, however, higher prevalence rates of $83.3 \%$ and $80 \%$ have been reported respectively on fresh vegetables and ready-to-eat salads (15). In Ghana, the most predominant bacteria reported in food include Enterobacter spp., Citrobacter spp., Klebsiella spp., and Escherichia spp. (20). An assessment of microbial quality of sampled salads, macaroni, "fufu," and red pepper in Accra had unacceptable levels of contamination $(69.7 \%)$ with mesophilic bacteria including Enterobacteriaceae (21).

Vegetable and crop cultivation without recourse to protocol on manure application is prone to contamination with pathogenic microorganisms that are also gifted with antimicrobial resistance features $(22,23)$. Some vegetable and crop farmers in Ghana flout the regulations on manure usage due to poor supervision by regulatory authorities that could eventually make vegetables and crops a haven for resistant strains including ESBLs. Pathogens could have been eliminated with good food preparation/processing practices in the food chain but that seems not to be effective. It must also be noted that produce can become contaminated during the distribution process and improper human handling $(23,24)$.

Deepening the risk of exposure of resistant bacteria to consumers is the fact that salad vegetables are normally eaten

TABLE 3 | Resistance pattern of fufu isolates.

\begin{tabular}{|c|c|c|c|c|c|c|c|c|c|c|c|c|c|c|c|}
\hline \multirow[t]{2}{*}{ Type of strain } & \multicolumn{14}{|c|}{ Antibiotic \% Resistance } & \multirow[t]{2}{*}{$P$ value } \\
\hline & GN & SXT & AMP & AMC & CIP & TET & CRO & CAZ & ERY & CTX & FOX & FEP & C & IPM & \\
\hline ESBL $(n=54)$ & 3.7 & 44.4 & 90.7 & 74.1 & 13.0 & 72.2 & 92.6 & 96.3 & 13.0 & 100.0 & 33.3 & 100.0 & 46.3 & 24.1 & 0.103 \\
\hline $\begin{array}{l}\text { Non- } \\
\text { ESBL }(n=17)\end{array}$ & 0.0 & 52.9 & 82.4 & 70.6 & 23.5 & 70.6 & 82.4 & 82.4 & 17.7 & 76.5 & 29.4 & 70.6 & 47.1 & 17.7 & \\
\hline
\end{tabular}

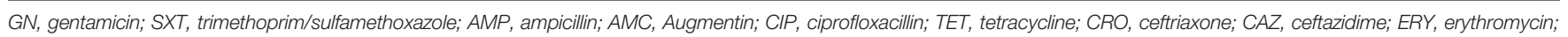
CTX, cefotaxime; FOX, cefoxitin; FEP, cefepime; C, chloramphenicol; IPM, imipenem. 
TABLE 4 | Resistance of ESBL-producing Salmonella and E. coli from food.

\begin{tabular}{|c|c|c|c|c|c|c|c|c|c|c|c|c|c|c|c|}
\hline \multirow[t]{2}{*}{ Isolates } & \multicolumn{14}{|c|}{ Antibiotic \% Resistance } & \multirow[t]{2}{*}{$P$ value } \\
\hline & GN & SXT & AMP & AMC & CIP & TET & CRO & CAZ & ERY & CTX & FOX & FEP & C & IPM & \\
\hline $\begin{array}{l}\text { Salmonella } \\
(\mathrm{n}=33)\end{array}$ & 15.2 & 51.5 & 57.6 & 57.6 & 30.3 & 39.4 & 81.8 & 78.8 & 55.6 & 81.8 & 36.4 & 84.9 & 6.1 & 3.0 & 0.002 \\
\hline $\begin{array}{l}\text { E. coli } \\
(n=41)\end{array}$ & 0.0 & 48.8 & 95.1 & 70.7 & 7.3 & 82.9 & 73.2 & 100.0 & 4.9 & 100.0 & 24.4 & 97.6 & 58.5 & 24.4 & \\
\hline
\end{tabular}

GN, gentamicin; SXT, cotrimoxazole; AMP, ampicillin; AMC, Augmentin; CIP, ciprofloxacillin; TET, tetracycline; CRO, ceftriaxone; CAZ, ceftazidime; ERY, erythromycin; CTX, cefotaxime; FOX, cefoxitin; FEP, cefepime; C, chloramphenicol; IPM, imipenem.

without any form of heat treatment, sometimes without adequate washing, thus has the potential for causing foodborne infections (25). Likewise, fufu, which is cooked up from boiled cassava and plantain, is traditionally prepared with bare hands when at room temperature and eaten with warm soup. The impact of food processing on the transfer of antimicrobial resistance to humans is widely reported (26). Minimal processing of food can lead to strained and/or sublethally damaged cells, and several studies have demonstrated that stress could influence the phenotypic antimicrobial resistance of microorganisms, increasing horizontal transmission of plasmids containing antimicrobial resistance genes by conjugation $(27,28)$. These bacteria can also survive the digestion process and may contribute to the spread of antimicrobial resistant genes to the normal flora of the intestinal tract (15).

Pathogen contamination of ready-to-eat food has been extensively described, and the presence of antibiotic-resistant bacteria can represent an additional risk factor, especially for the elderly and the immunosuppressed. Our ESBL strains from the sampled food (salad and fufu) gave divergent resistance patterns. The salad ESBL strains showed absolute sensitivity to imipenem and chloramphenicol and most resistance to the third-generation cephalosporins, cefotaxime $(70 \%)$, ceftriaxone $(85 \%)$, and ceftazidime $(70 \%)$. The non- $\beta$-lactam drugs that were least effective included erythromycin and cotrimoxazole. On the contrary, the fufu ESBL strains showed resistance of $24.1 \%$ to imipenem and highest resistance to the penicillins (ampicillin, 90.7\%; Augmentin, 74.1\%) and the third-generation cephalosporins (ceftriaxone, $100 \%$; cefotaxime, $100 \%$; ceftazidime, 96.3\%). The least potent non- $\beta$-lactam drugs were tetracycline and cotrimoxazole. A stimulating phenomenon encountered was the analogous resistance pattern exhibited by the ESBL and non-ESBL strains. Although the difference in resistance was statistically insignificant $(\mathrm{p}=0.975, \mathrm{p}=0.103)$, drugs that were effective among the ESBLs were equally so among the non-ESBL strains, likewise the ineffective drugs. In related studies, $100 \%$ resistance to cefotaxime (29) and amoxicillin $(18,30)$ have been reported, while resistance rates of $73.3 \%$ (gentamicin), $63.2 \%$ (cotrimoxazole), and $26.3 \%$ (ciprofloxacin) were described among ESBL isolates (29).

Species-specific resistance revealed $E$. coli ESBL strains to be significantly $(\mathrm{p}=0.002)$ greater than the Salmonella ESBL species. The most effective drugs against E. coli included gentamicin, ciprofloxacin, and erythromycin, while imipenem and chloramphenicol were potent against the Salmonella species, with observed resistance below $10 \%$. A similar study in Nepal found cotrimoxazole and gentamicin as the most effective drugs for both E. coli and Salmonella isolates (18), but in Nigeria, authors found the entire Salmonella isolates from salads resistant to amoxicillin (30). Correspondingly, the penicillins (ampicillin, Augmentin) performed poorly against both our E. coli and Salmonella strains, which could be credited to facile hydrolysis of the $\beta$-lactam ring by the pathogens. Multiple drug resistance was exhibited in all our ESBL-producing species that is comparable to a study in Bangladesh where 100\% Multiple drug resistance (MDR) was observed in E. coli and Salmonella isolates from green salads (31).

The varying resistance trends observed across the different geographical settings depict the pattern of drug usage and management in these regions. For instance, some studies have reported high resistance $(73.7 \%-94.8 \%)$ to aminoglycosides (29, 32 ), but it has been fairly sensitive to isolated pathogens from food, animals, and clinical and environmental sources in Ghana. Factors accounting for this effectiveness could be drug availability, drug administration, and cost. Affordable and readily accessible over-the-counter drugs have been misused and abused over the years by consumers, veterinarians, farmers, clinicians, and patients, rendering drugs including $\beta$ lactams, tetracyclines, erythromycins, and cotrimoxazole empirically useless. The aminoglycosides and the carbapenems are infrequently used and not readily accessible due to cost, as well as being last-line treatment drugs for difficult-to-manage

TABLE 5 | MAR index of isolates from food samples.

\begin{tabular}{|c|c|c|c|c|c|}
\hline \multirow[t]{2}{*}{ Isolate } & \multicolumn{2}{|c|}{ ESBL } & \multicolumn{2}{|c|}{ Non-ESBL } & \multirow{2}{*}{$\begin{array}{c}\text { Overall } \\
\text { MAR }\end{array}$} \\
\hline & Fufu & Salad & Fufu & Salad & \\
\hline E. coli & 0.59 & 0.43 & 0.61 & 0.37 & 0.56 \\
\hline Salmonella & 0.53 & 0.45 & 0.38 & 0.48 & 0.48 \\
\hline
\end{tabular}

ESBL, extended-spectrum $\beta$-lactamase; MAR, multiple antibiotic resistance. 
infections. The MAR indices of the E. coli and Salmonella isolates being greater than 0.2 indicate that our study setting is an area where antibiotics are frequently used according to the interpretation of Rotchell and Paul (33).

This study could not provide data on the source of contamination, bacterial quality of water for the food preparation, and molecular characterization of isolates which is a limitation. However, it determined the extent of contamination of salads and fufu with E. coli and Salmonella species and their multidrug resistance pattern along with ESBL production, which has contributed to food safety data in a region where such information is very limited. Foodborne illnesses are significant causes of morbidity and mortality; therefore, the microbiological quality of food should be monitored and regulated to ensure public health safety.

\section{CONCLUSION}

The results indicated substantial contamination of ready-to-eat salads and fufu with multiple resistant ESBL strains. The presence of pathogenic bacteria in food is a public health hazard. This study suggests that street food constitute a possible route for the spread of ESBLs, thus meriting particular

\section{REFERENCES}

1. World Health Organization. WHO Estimates of the Global Burden of Foodborne Diseases: Foodborne Disease Burden Epidemiology Reference Group 2007-2015. Available at: http://apps.who.int/iris/bitstream/10665/ 199350/1/9789241565165_eng.pdf?ua=1.

2. Al Mamun M, Rahman SMM, Turin TC. Microbiological Quality of Selected Street Food Items Vended by School-Based Street Food Vendors in Dhaka, Bangladesh. Int J Food Microbiol (2013) 166:413-8. doi: 10.1016/ j.ijfoodmicro.2013.08.007

3. Noor R. Microbiological Quality of Commonly Consumed Street Foods in Bangladesh. Nutr Food Sci (2016) 46(1):130-41. doi: 10.1108/NFS-08-20150091

4. Arslan S, Eyi A. Antimicrobial Resistance and ESBL Prevalence in Escherichia Coli From Retail Meats. J Food Saf (2011) 31(2):262-7. doi: 10.1111/j.1745

5. Ben-Ami R, Schwaber MJ, Navon-Venezia S, Schwartz D, Giladi M, Chmelnitsky I, et al. Influx of Extended-Spectrum Beta-LactamaseProducing Enterobacteriaceae Into the Hospital. Clin Infect Dis (2006) 42 (7):925-34. doi: 10.1086/500936

6. Saravanan M, Ramachandran B, Barabadi H. The Prevalence and Drug Resistance Pattern of Extended Spectrum $\beta$-Lactamases (ESBLs) Producing Enterobacteriaceae in Africa. Microbial Pathogen (2018) 114:180-92. doi: 10.1016/j.micpath.2017.11.061

7. Zurfluh K, Nuesch-Inderbinen M, Morach M, Berner AZ, Hachler H, Stephan R. Extended424 Spectrum- $\beta$-Lactamase-Producing Enterobacteriaceae Isolated From Vegetables Imported From the 425 Dominican Republic, India, Thailand, and Vietnam. Appl Environ Microbiol (2015) 42681 (9):3115-20. doi: 10.1128/AEM.00258-15

8. Collignon P, Aarestrup FM, Irwin R, McEwen S. Human Deaths and Thirdgeneration Cephalosporin Use in Poultry. Europe Emerg Infect Dis (2013) 19:1339-40. doi: 10.3201/eid1908.120681

9. Chantziaras I, Boyen F, Callens B, Dewulf J. Correlation Between Veterinary Antimicrobial Use and Antimicrobial Resistance in Food-Producing Animals: A Report on Seven. J Antimicrobial Chem (2014) 69(3):827-34. doi: 10.1093/ jac/dkt 443

10. International Organization for Standardization (ISO). Laboratory Protocol "Isolation of Salmonella Spp. From Food and Animal Faces" (2002). attention in terms of street food safety and its threat in serious food poisoning outbreaks.

\section{DATA AVAILABILITY STATEMENT}

The raw data supporting the conclusions of this article will be made available by the authors without undue reservation.

\section{AUTHOR CONTRIBUTIONS}

AK was involved in the conception, study design, and writing of the article. CS contributed to the drafting of the article. DY and SK were involved in sample collection and processing as well as data analysis. All authors contributed to the article and approved the submitted version.

\section{ACKNOWLEDGMENTS}

We thank all the food vendors who sold their food to us for this project and also the Antimicrobial Resistance Unit of the Faculty of Veterinary Medicine of the Complutense University of Madrid, Spain, for assisting us in procuring some of our materials for this work.

Available at: https://www.iso.org/obp/ui/\#iso (Accessed on 02 April 2015).

11. CLSI. Performance Standards for Antimicrobial Susceptibility Testing: 16th Informational Supplement. In: Table 2a. Screening and Confirmatory Tests for ESBLs in Klebsiella Pneumoniae, K. Oxytoca, Escherichia Coli and Proteus Mirabilis, vol. 26. . Wayne, PA: Clinical and Laboratory Standards Institute (2006). p. M100-S16.

12. Krumperman PH. Multiple Antibiotic Resistance Indexing of Escherichia Coli to Indentify High-Risk Sources of Fecal Contamination of Foods. Appl Environ Microbiol (1983) 46:165-70. doi: 10.1128/aem.46.1.165170.1983

13. Ye Q, Wu Q, Zhang S, Zhang J, Yang G, Wang H, et al. Antibiotic-Resistant Extended Spectrum B-Lactamase- and Plasmid-Mediated AmpCProducing Enterobacteriaceae Isolated From Retail Food Products and the Pearl River in Guangzhou. China Front Microbiol (2017) 8:96. doi: 10.3389/ fmicb.2017.00096

14. Freitag C, Michael GB, Jun L, Kadlec K, Yang W, Hassel M, et al. Occurrence and Characterisation of ESBL-Encoding Plasmids Among Escherichia Coli Isolates From Fresh Vegetables. Vet Microbio (2018) 21:63-9. doi: 10.1016/ j.vetmic.2018.03.028

15. Iseppi R, de Niederhäusern S, Bondi M, Messi P, Sabia C. Extended-Spectrum Blactamase, AmpC, and MBL-Producing Gram-Negative Bacteria on Fresh Vegetables and Ready-to-Eat Salads Sold in Local Markets. Microb Drug Resist (2018) 24:1156-64. doi: 10.1089/mdr.2017.0198

16. Raphael E, Wong LK, Riley LW. Extended-Spectrum Beta-Lactamase Gene Sequences in Gramnegative Saprophytes on Retail Organic and Nonorganic Spinach. Appl Environ Microbiol (2011) 77(5):1601-7. doi: 10.1128/AEM. 02506-10

17. Reuland EA, al Naiemi N, Raadsen SA, Savelkoul PHM, Kluytmans JAJW, VandenbrouckeGrauls CMJE. Prevalence of ESBL-Producing Enterobacteriaceae in Raw Vegetables. Eur J Clin Microbiol Infect Dis (2014) 33:1843-6. doi: 10.1007/s10096-014-2142-7

18. Sapkota S, Adhikari S, Pandey A, Khadka S, Dhakal MA, Kandel H, et al. Multi-Drug Resistant Extended-Spectrum Beta-Lactamase Producing E. Coli and Salmonella on Raw Vegetable Salads Served at Hotels and Restaurants in Bharatpur, Nepal. BMC Res Notes (2019) 12:516. doi: 10.1186/s13104019-4557-9 
19. Mesa RJ, Blanc V, Blanch AR, Cortés P, González JJ, Lavilla S, et al. ExtendedSpectrum Betalactamase-Producing Enterobacteriaceae in Different Environments (Humans, Food, Animal Farms and Sewage). J Antimicrob Chemother (2006) 58(1):211-5. doi: 10.1093/jac/dkl211

20. Saba SKC, Gonzalez-Zorn B. Microbial Food Safety in Ghana- Metaanalysis. J Infect Develop Countries (2012) 6(12):828e835. doi: 10.3855/jidc.1886

21. Mensah P, Yeboah-Manu D, Owusu-Darko K, Ablordey A. Street Foods in Accra, Ghana: How Safe are They? Bull World Health Organisation (2002) 80 (7):546-54. doi: 10.1590/S0042-96862002000700006

22. World Health Organization. WHO Guidelines for the Safe Use of Wastewater, Excreta and Greywater. Vol 4 Excreta and Greywater Use in Agriculture. World Health Organization, Geneva, Switzerlandcountries. J Antimicrob Chemother (2006) 69:827-34. doi: 10.1093/jac/dkt

23. Schwaiger K, Helmke K, Hölzel CS, Bauer J. Antibiotic Resistance in Bacteria Isolated From Vegetables With Regards to the Marketing Stage (Farm vs. Supermarket). Int J Food Microbiol (2011) 148(3):191-6. doi: 10.1016/ j.ijfoodmicro.2011.06.001

24. van Hoek AH, Veenman C, van Overbeek WM, Lynch G, de Roda Husman AM, Blaak H. Prevalence and Characterization of ESBL- and AmpC Producing Enterobacteriaceae on Retail Vegetables. Int J Food Microbiol (2015) 204:1-8. doi: 10.1016/j.ijfoodmicro.2015.03.014

25. Beuchat LR, Larry R. Pathogenic Microorganism Associated With Fresh Produce. J Food Protect (2000) 13:204-16. doi: 10.4315/0362-028X-59.2.204

26. Verraes C, Van Boxstael S, Van Meervenne E, Van Coillie E, Butaye P, Catry B, et al. Antimicrobial Resistance in the Food Chain: A Review. Int J Environ Res Public Health (2013) 10:2643-69. doi: 10.3390/ijerph10072643

27. McMahon MAS, Blair IS, Moore JE, McDowell DA. The Rate of Horizontal Transmission of Antibiotic Resistance Plasmids is Increased in Food Preservationstressed Bacteria. J Appl Microbiol (2007) 103:1883-8. doi: 10.1111/j.1365-2672.2007.03412.x

28. Ganjian H, Nikokar I, Tieshayar A, Mostafaei A, Amirmozafari N, Kiani S. Effects of Salt Stress on the Antimicrobial Drug Resistance and Protein Profile of Staphylococcus Aureus. Jundishapur J Microbiol (2012) 5:328-31. doi: 10.5812/kowsar.20083645.2375

29. Kim HS, Chon JW, Kim YJ, Kim DH, Kim MS, Seo KH. Prevalence and Characterization of Extended-Spectrum-B-Lactamase-Producing Escherichia
Coli and Klebsiella Pneumoniae in Ready-to-Eat Vegetables. Int J Food Microbiol (2015) 207:83-6. doi: 10.1016/j.ijfoodmicro.2015.04.049

30. Adeshina GO, Jibo SD, Agu VE. Antibacterial Susceptibility Pattern of Pathogenic Bacteria Isolates From Vegetable Salad Sold in Restaurants in Zaria, Nigeria. J Microbiol Res (2012) 2(2):5-11. doi: 10.5923/ j.microbiology.20120202.02

31. Nipa MN, Mazumdar RM, Hasan MM, Fakruddin MD, Islam S, Bhuiyan HR, et al. Prevalence of Multi Drug Resistant Bacteria on Raw Salad Vegetables Sold in Major Markets of Chittagong City, Bangladesh. Middle-East J Sci Res (2011) 10(1):70-7.

32. Richter L, Du Plessis EM, Duvenage S, Korsten L. (2019). Occurrence, Identification, and Antimicrobial Resistance Profiles of Extended-Spectrum and AmpC $\beta$-Lactamase-Producing Enterobacteriaceae from Fresh Vegetables Retailed in Gauteng Province, South Africa. Foodborne Pathogens and Disease 16(6):421-7. doi: 10.1089/fpd.2018.2558

33. Rotchell D, Paul D. Multiple Antibiotic Resistance Index. Fitness and Virulence Potential in Respiratory Pseudomonas Aeruginosa From Jamaica. J Med Microbiol (2016) 65:251- 271. doi: 10.1099/jmm.0. 000229

Conflict of Interest: The authors declare that the research was conducted in the absence of any commercial or financial relationships that could be construed as a potential conflict of interest.

Publisher's Note: All claims expressed in this article are solely those of the authors and do not necessarily represent those of their affiliated organizations, or those of the publisher, the editors and the reviewers. Any product that may be evaluated in this article, or claim that may be made by its manufacturer, is not guaranteed or endorsed by the publisher.

Copyright (c) 2022 Karikari, Kpordze, Yamik and Saba. This is an open-access article distributed under the terms of the Creative Commons Attribution License (CC BY). The use, distribution or reproduction in other forums is permitted, provided the original author(s) and the copyright owner(s) are credited and that the original publication in this journal is cited, in accordance with accepted academic practice. No use, distribution or reproduction is permitted which does not comply with these terms. 